\title{
Post-mastectomy sensory recovery and restoration
}

\author{
Kristy L. Hamilton ${ }^{1}$, Katarzyna E. Kania ${ }^{1}$, Aldona J. Spiegel ${ }^{2}$ \\ ${ }^{1}$ Division of Plastic and Reconstructive Surgery, Baylor College of Medicine, Houston, TX, USA; ${ }^{2}$ Weill Cornell Medical College, Houston \\ Methodist Institute for Reconstructive Surgery, Houston, TX, USA \\ Contributions: (I) Conception and design: AJ Spiegel; (II) Administrative support: AJ Spiegel; (III) Provision of study materials or patients: AJ Spiegel; \\ (IV) Collection and assembly of data: KL Hamilton; (V) Data analysis and interpretation: KL Hamilton; (VI) Manuscript writing: All authors; (VII) \\ Final approval of manuscript: All authors. \\ Correspondence to: Aldona J. Spiegel, MD. 6560 Fannin, Suite 2200, Houston, TX 77030, USA. Email: aspiegel@HoustonMethodist.org.
}

\begin{abstract}
Breast sensation has recently become an integral aspect of the reconstructive goal after mastectomy and is an important consideration for many patients. Neurotization techniques using primary coaptation, autograft, allograft, or nerve conduit have been used for autologous flaps, such as the deep inferior epigastric perforator (DIEP) flap. Outcomes have shown improved sensation and faster sensory recovery in the flap skin in immediate neurotized DIEP flap breast reconstructions compared to delayed reconstruction. Breast flap neurotization during reconstruction is a rapid and simple procedure with minimal morbidity. An improved understanding of breast anatomy and innovative modifications to breast reconstruction have made the restoration of breast sensation achievable, and promising results have been obtained with respect to sensory return and patient satisfaction.
\end{abstract}

Keywords: Breast reconstruction; breast flaps; autologous-based reconstruction; neurotization; sensory recovery; post-mastectomy sensation

Submitted Feb 14, 2020. Accepted for publication Mar 06, 2020.

doi: 10.21037 /gs.2020.03.22

View this article at: http://dx.doi.org/10.21037/gs.2020.03.22

\section{Introduction}

Breast cancer is exceedingly common; one in eight American women will develop breast cancer over the course of their lifetimes. However, breast cancer mortality rates have also dropped by over a third since 1990 thanks to early detection and evolving treatment modalities (1). With this increase in the survival rate, breast reconstruction has become increasingly common. Indeed, over 100,000 breast reconstructions were performed in the United States in 2016 (2). This trend is encouraging, given the significant psychosocial benefits of breast reconstruction established in the literature (3). The presence of breast sensation, in particular, is linked to increased patient satisfaction following reconstruction (4).

The two main types of breast reconstruction are autologous reconstruction, which uses the patient's own tissue, and implant-based reconstruction. Deep inferior epigastric perforator (DIEP) flap reconstruction, which uses excess tissue from the lower abdomen, remains the gold standard in autologous breast reconstruction. It is popular for its natural appearance and feel, its long-term aesthetic result, and general patient satisfaction $(5,6)$. Over the past two decades, the focus has shifted from the microsurgical success of the DIEP flap to improving the aesthetics of the reconstructed breast and the abdominal donor site, and outcomes approaching those of aesthetic plastic surgery have been achieved in many cases. Less attention has been paid to functional restoration, namely, the restoration of sensation to the mastectomy skin following oncologic surgery and subsequent reconstruction.

Following a mastectomy, women suffer the loss of a key physical component of femininity and sexuality from both a visual and sensory perspective. Many women are not advised about the sensory deficits they will encounter following surgery, which can range from diminished to absent sensation and which can be debilitating for some 
patients. In addition, the lack of protective sensation can pose serious problems; patients have been known to suffer thermal injuries from common household items due to breast numbness $(7,8)$. Preserving and restoring postmastectomy breast sensation has thus become the latest frontier in breast reconstruction.

\section{Surgical anatomy and technique}

The nipple-areolar complex is innervated primarily by the third, fourth, and fifth intercostal nerves, and the remainder of the breast also includes innervation from the second and sixth intercostal nerves and the supraclavicular nerves (9). The intercostal nerves give off lateral and anterior cutaneous branches. The lateral branches are sacrificed during a mastectomy as they enter the gland in the deep plane and then provide sensory branches to the skin. The anterior branches travel in the subcutaneous plane and can, therefore, sometimes be spared during a nipple-sparing mastectomy, which can help preserve sensation in the mastectomy skin regardless of the type of reconstructive surgery the patient might subsequently undergo.

In autologous reconstruction, either the anterior or lateral branches of the intercostal nerves, which are severed during the mastectomy, can be used as the recipient nerves. The recipient nerve of choice is the anterior branch of the third intercostal nerve, which arises medially in the intercostal space, slightly inferior to the third rib and medial to the sternum. This nerve is ideally situated as it lies in the same operative field as the vascular anastomoses for the flap. To maximize the length of the recipient nerve, it is dissected along the course it travels with the pectoral intercostal perforator to innervate the breast skin (10).

As the DIEP flap is the most commonly used flap in autologous breast reconstruction, the neuroanatomy of available donor nerves in the abdomen is relevant. In an anatomical study, Mori et al. demonstrated that the anterior cutaneous branches on the tenth, eleventh, and twelfth intercostal nerves, which enter the rectus abdominus flap slightly superior to the skin paddle in question, ought to be innervated to maximize flap sensation after innervation. The appropriate nerves for coaptation are found in the inferior half of the flap (11). The sensory components of the intercostal nerves pierce the rectus abdominus and follow the same course as the perforating vessels to innervate the abdominal skin. When one of these nerves is identified at the level of the fascia, it can be dissected below the fascia for additional few centimeters to allow for easier coaptation to the chest intercostals. Dissection ceases at the point where the sensory component meets with the motor contribution of the nerve to avoid harvesting unnecessary motor nerves, to preserve the neuro-integrity of the abdominal wall, and to avoid abdominal bulges.

Nerve coaptation can then be performed using autografts, allografts, or nerve conduit tubes, depending on the gap. As with any nerve repair, the goal is a tension-free repair. In the peripheral nerve literature, a primary nerve repair is preferred as it yields the best outcomes, but this has not been clearly delineated in the breast reconstruction literature. If there is a gap between the recipient and donor nerves, coaptation can be achieved with a nerve autograft, which can be harvested from another donor nerve from the flap, usually up to $3 \mathrm{~cm}$ in length. Most of the lower perforators, which are rarely used for flap perfusion, have an accompanying nerve that may be used as an autograft. If autograft is unavailable, a nerve allograft is also an option. Finally, a gap of up to $3 \mathrm{~cm}$ can be addressed with a nerve conduit, although the nerve repair literature generally suggests these gaps be limited to $5-10 \mathrm{~mm}$ if possible for best outcomes (12-14).

Some alternative flaps for breast reconstruction have sensory donor nerves which can be coapted. The profunda artery perforator and transverse upper gracilis flaps include a sensory branch of the femoral nerve. The superior and inferior gluteal perforator flaps include the superior and inferior gluteal nerves, respectively, for sensation. The lateral thigh perforator flap includes a branch of the lateral femoral cutaneous nerve. All of these sensory nerves are options for sensory nerve coaptation in autologous breast reconstruction. Cornelissen et al. demonstrated that while the innervated DIEP flap becomes more sensitive to pressure over time compared to a healthy native breast, the profunda artery perforator flap, lateral thigh perforator flap, superior gluteal artery flap, and transverse upper gracilis flap all demonstrate less sensitivity to monofilament pressure compared to a healthy breast (15).

\section{Natural history of post-mastectomy sensory recovery}

Debate relating to the recovery of sensation in postmastectomy skin after flap reconstruction dates back to the 1990s and stems from the argument that the skin recovers sensation regardless of flap neurotization (16,17). In 1999, Blondeel et al. noted that while some sensation was found to return to skin flaps that were not innervated, flaps that 
had undergone neurotization were found to have earlier spontaneous recovery of sensation and higher-quality sensation and were more likely to have erogenous sensation restored (18). Several subsequent studies subsequently have obtained similar results, showing that while some sensation may recover spontaneously, neurotizing an underlying autologous flap or using a sensate flap yields better results (19-21). The topic has become increasingly less controversial with the advent of advanced technologies that can characterize sensation in relation to numerical pressure readings, such as pressure-specified sensory devices (PSSD) (22). A common criticism of the traditional Semmes-Weinstein monofilament test lies in its user-dependence and its consequent potential unreliability. However, the use of devices such as the PSSD, has partially ameliorated this concern.

In a retrospective study by the senior author of this paper, neurotization of the DIEP flap using the third anterior intercostal nerves resulted in significantly improved sensory recovery in the flap skin, which was even greater than that in the native mastectomy skin. Sensory return was found to be greater in immediate reconstructions than in delayed reconstructions. Furthermore, sensation recovered in DIEP flaps neurotized using a nerve conduit was significantly better than in corresponding areas of the DIEP flaps neurotized by direct coaptation. This observation suggests that using a nerve conduit with a small gap may allow the fascicles to align appropriately between the two ends of the nerve (23).

\section{Conclusions}

The restoration of sensation to mastectomy skin is a key component of the breast reconstruction process. Efforts should be made to preserve sensory nerves as much as oncologically possible during the mastectomy and to restore sensation through nerve coaptation during autologous breast reconstruction. Breast flap neurotization during reconstruction is a simple and fast procedure that does not contribute to morbidity. Given the evolving body of literature demonstrating improvements in sensory recovery and patient satisfaction following neurotization and nerve preservation, efforts should always be made to preserve and restore sensation in the reconstructed breast where possible.

\section{Acknowledgments}

Funding: None.

\section{Footnote}

Provenance and Peer Review: This article was commissioned by the Guest Editors (Charles E. Butler, Carrie Chu, and Margaret Roubaud) for the series "New Frontiers in Breast Reconstruction" published in Gland Surgery. The article was sent for external peer review organized by the Guest Editors and the editorial office.

Conflicts of Interest: All authors have completed the ICMJE uniform disclosure from (available at http://dx.doi. org/10.21037/gs.2020.03.22). The series "New Frontiers in Breast Reconstruction" was commissioned by the editorial office without any funding or sponsorship. The authors have no other conflicts of interests to declare.

Ethical Statement: The authors are accountable for all aspects of the work in ensuring that questions related to the accuracy or integrity of any part of the work are appropriately investigated and resolved.

Open Access Statement: This is an Open Access article distributed in accordance with the Creative Commons Attribution-NonCommercial-NoDerivs 4.0 International License (CC BY-NC-ND 4.0), which permits the noncommercial replication and distribution of the article with the strict proviso that no changes or edits are made and the original work is properly cited (including links to both the formal publication through the relevant DOI and the license). See: https://creativecommons.org/licenses/by-nc$\mathrm{nd} / 4.0 /$.

\section{References}

1. DeSantis C, Ma J, Bryan L, et al. Breast cancer statistics, 2013. CA Cancer J Clin 2014;64:52-62.

2. Liu D. New plastic surgery statistics and breast reconstruction trends. American Society of Plastic Surgeons, 14 Mar 2017. Available online: https://www. plasticsurgery.org/news/blog/new-plastic-surgerystatistics-and-breast-reconstruction-trends

3. Phan R, Hunter-Smith DJ, Rozen WM. The use of patient reported outcome measures in assessing patient outcomes when comparing autologous to alloplastic breast reconstruction: a systematic review. Gland Surg 2019;8:452-60.

4. Cornelissen AJM, Beugels J, van Kuijk SMJ, et al. Sensation of the autologous reconstructed breast improves 
quality of life: a pilot study. Breast Cancer Res Treat 2018;167:687-95.

5. Howard-McNatt MM. Patients opting for breast reconstruction following mastectomy: an analysis of uptake rates and benefits. Breast Cancer 2013;5:9-15.

6. Hu ES, Pusic AL, Waljee JF, et al. Patient-reported aesthetic satisfaction with breast reconstruction during the long-term survivorship period. Plast Reconstr Surg 2009;124:1-8.

7. Faulkner HR, Colwell AS, Liao EC, et al. Thermal Injury to Reconstructed Breasts from Commonly Used Warming Devices: A Risk for Reconstructive Failure. Plast Reconstr Surg Glob Open 2016;4:e1033.

8. Enajat M, Rozen WM, Audolfsson T, et al. Thermal injuries in the insensate deep inferior epigastric artery perforator flap: case series and literature review on mechanisms of injury. Microsurgery 2009;29:214-7.

9. Sarhadi NS, Dunn JS, Lee FD, et al. An anatomical study of the nerve supply of the breast, including the nipple and areola. Br J Plast Surg 1996;49:156-64.

10. Spiegel AJ, Salazar-Reyes H, Izaddoost S, et al. A novel method for neurotization of deep inferior epigastric perforator and superficial inferior epigastric artery flaps. Plast Reconstr Surg 2009;123:29e-30e.

11. Mori H, Akita K, Hata Y. Anatomical study of innervated transverse rectus abdominis musculocutaneous and deep inferior epigastric perforator flaps. Surg Radiol Anat 2007;29:149-54.

12. Weber RA, Breidenbach WC, Brown RE, et al. A randomized prospective study of polyglycolic acid conduits for digital nerve reconstruction in humans. Plast Reconstr Surg 2000;106:1036-45.

13. Ducic I, Safa B, DeVinney E. Refinements of nerve repair with connector-assisted coaptation. Microsurgery 2017;37:256-63.

14. Ducic I, Fu R, Iorio M. Innovative Treatment of

Cite this article as: Hamilton KL, Kania KE, Spiegel AJ. Post-mastectomy sensory recovery and restoration. Gland Surg 2021;10(1):494-497. doi: 10.21037/gs.2020.03.22
Peripheral Nerve Injuries. Ann Plast Surg 2012;68:180-7.

15. Cornelissen AJM, Beugels J, Lataster A, et al. Comparing the sensation of common donor site regions for autologous breast reconstruction to that of a healthy breast. J Plast Reconstr Aesthet Surg 2018;71:327-35.

16. Stromps JP, Bozkurt A, Grieb G, et al. Spontaneous reinnervation of deep inferior epigastric perforator flaps after delayed breast reconstruction. J Reconstr Microsurg 2016;32:169-77.

17. Magarakis M, Venkat R, Dellon AL, et al. Pilot study of breast sensation after breast reconstruction: evaluating the effects of radiation therapy and perforator flap neurotization on sensory recovery. Microsurgery 2013;33:421-31.

18. Blondeel PN, Demuynck M, Mete D, et al. Sensory nerve repair in perforator flaps for autologous breast reconstruction: sensational or senseless? Br J Plast Surg 1999;52:37-44.

19. Yano K, Hosokawa K, Takagi S, et al. Breast Reconstruction using the sensate latissimus dorsi musculocutaneous flap. Plast Reconst Surg 2002;109:1897-902.

20. Heine N, Koch C, Brebant V, et al. Breast sensitivity after mastectomy and autologous reconstruction. Clin Hemorheol Microcirc 2017;67:459-65.

21. Beugels J, Cornelissen AJM, van Kuijk SMJ, et al. Sensory recovery of the breast following innervated and noninnervated DIEP flap breast reconstruction. Plast Reconstr Surg 2019;144:178e-188e.

22. Lavery LA, Najafi B. Accuracy and durability of SemmesWeinstein monofilaments: What is the useful service life? Diabetes Res Clin Pract 2012;97:399-404.

23. Spiegel AJ, Menn ZK, Eldor L, et al. Breast Reinnervation: DIEP Neurotization Using the Third Anterior Intercostal Nerve. Plast Reconstr Surg Glob Open 2013;1:e72. 